\title{
Insecticidal and neuroblocking potencies of variants of the thiazolidine moiety of thiacloprid and quantitative relationship study for the key neonicotinoid pharmacophore
}

\author{
Shinzo Kagabu, ${ }^{*}$ Keiichiro Nishimura, ${ }^{\dagger}$ Yuji NARUSE ${ }^{\dagger \dagger}$ and Ikuya OHNO \\ Department of Chemistry, Faculty of Education, Gifu University, Gifu 501-1193, Japan \\ ${ }^{\dagger}$ Research Institute for Advanced Science and Technology, Osaka Prefecture University, Sakai, Osaka 599-8570, Japan

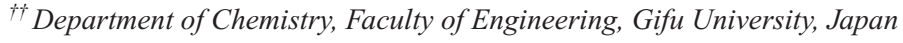

(Received July 26, 2007; Accepted October 19, 2007)

\begin{abstract}
The pharmacophore of the neonicotinoid insecticide thiacloprid, cyanoiminothiazolidine, was modified to heterocycles such as imidazolidine, pyrrolidine and oxazolidine (the central ring hereafter). Their 6-chloro3-pyridylmethyl or 5-chloro-3-thiazolylmethyl derivatives were examined for insecticidal activity against the American cockroach by injection and neuroblocking activity using the cockroach ganglion. The derivatives showed strong insecticidal activity with the minimum lethal dose (MLD) of about 10 nmol, which were however mostly weaker than the corresponding nitromethylene or nitroimine compounds. The activity was enhanced in the presence of synergists. The neuroblocking effect of cyanoimino compounds was at the micromolar level. Quantitative analysis for 23 variants of the key pharmacophore, constructed with the central ring conjugated to an $\mathrm{NCN}, \mathrm{CHNO}_{2}$, or $\mathrm{NNO}_{2}$, showed that the neuroblocking potency is proportional to the Mulliken charge on the nitro oxygen atom or cyano nitrogen atom. The optimum $\log P$ value was evaluated as 1.19. The equation for the insecticidal- $v s$. the neuroblocking-potencies indicated that both potencies are related proportionally with each other when the other factors are the same. C Pesticide Science Society of Japan
\end{abstract}

Keywords: thiacloprid, QSAR, pharmacophore, neuroblocking activity, Mulliken charge.

\section{Introduction}

In the preceding paper ${ }^{1)}$ we analyzed the relationship of the neuroblocking potencies of variants of the imidazolidine moiety of imidacloprid-related nitroimine and nitromethylene compounds to the physicochemical factors (Fig. 1), and derived a quantitative equation indicating that the neuroblocking potency is proportional both to the Mulliken charge on the nitro oxygen atom and the octanol-water partition coefficient $\log P$.

In the previous paper we did not addressed the cyanoiminoimidazolidine variants. Commercial products thiacloprid $(23)^{2,3)}$ and acyclic acetamiprid ${ }^{4)}$ are sharing this moiety, and compounds with this pharmacophore have been a target for insecticidal, physiological or biochemical study. ${ }^{5-10)}$ In this

\footnotetext{
* To whom correspondence should be addressed.

E-mail: kagabus@gifu-u.ac.jp

Published online December 28, 2007

(C) Pesticide Science Society of Japan
}

paper we report the insecticidal and neuroblocking activities of five cyanoimine variants, the measured $\log P$ values, and the calculated quantum chemical factors following the previous method. The goal of the study is to attain an integrated quantitative relationship between the biological activity and the physicochemical factors for the key pharmacophore with three representative electron-withdrawing groups $\mathrm{NNO}_{2}$, $\mathrm{CHNO}_{2}$ and the newly added $\mathrm{NCN}$.

\section{Materials and Methods}

\section{Preparation of compounds}

All melting points (mp) are uncorrected. IR spectra were measured with a Perkin Elmer FTIR 1600 spectrometer. NMR spectra were obtained by a Varian Gemini $2000 \mathrm{C} / \mathrm{H}(400$ $\mathrm{MHz}$ ). The chemical shifts were recorded in $\delta(\mathrm{ppm})$ and the coupling constants $J$ in $\mathrm{Hz}$. Mass spectra were recorded by Jeol JMS-700. Compounds 18, ${ }^{11)} \mathbf{1 9}^{12)}$ and 23 (thiacloprid) ${ }^{2}$ were prepared according to the described procedures.

3-(2-Chloropyridin-5-ylmethyl)-2-(cyanoimino)-oxazolidine (20). 


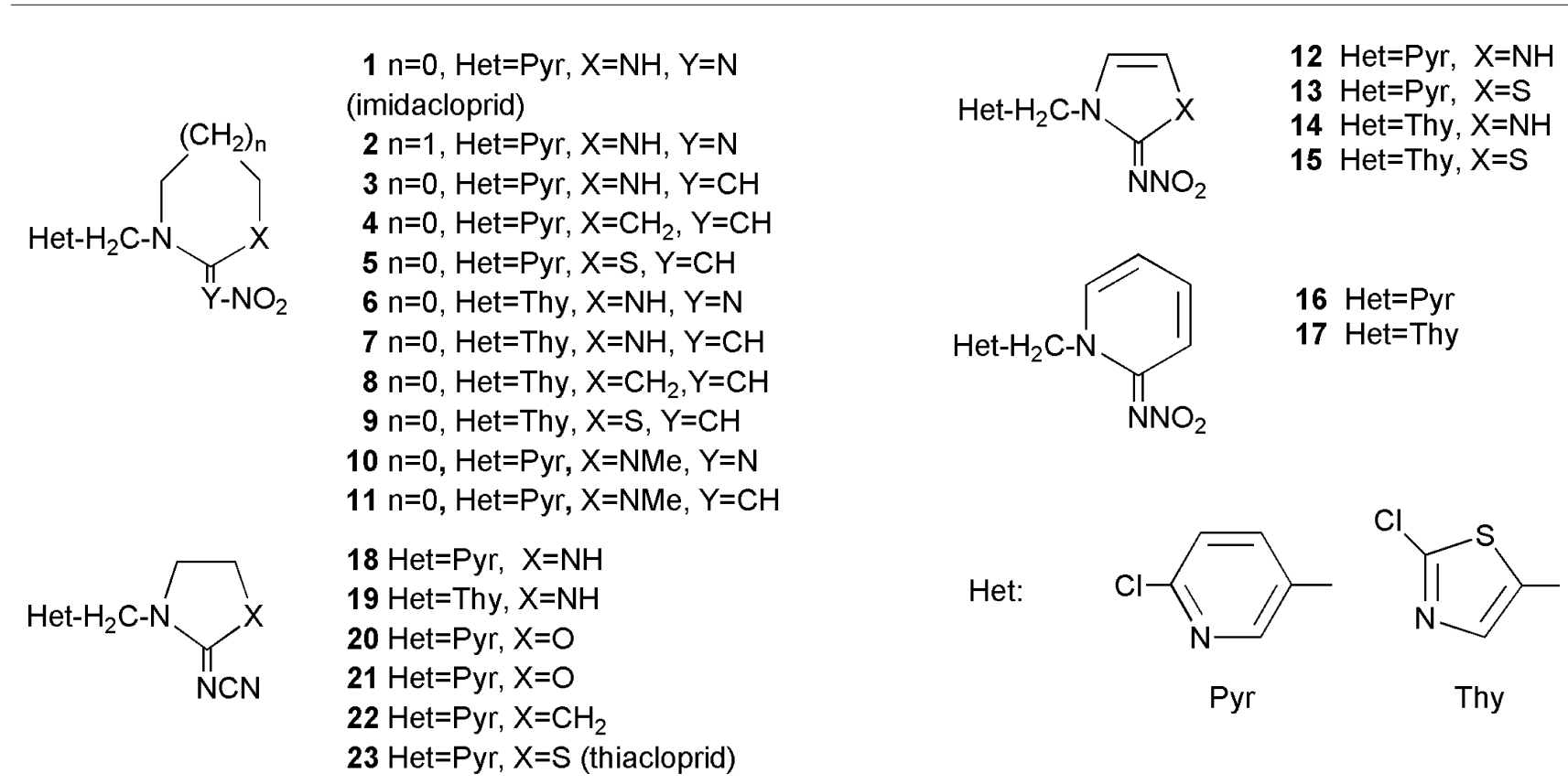

Fig. 1. Tested neonicotinoid compounds.

To an ice-cooled solution of 2-cyanoimino-oxazolidine ( $400 \mathrm{mg}, 3.6 \mathrm{mmol})$ in DMF $(20 \mathrm{ml})$ was added in small portions sodium hydride ( $60 \%$ oil dispersion; $182 \mathrm{mg}, 4.6 \mathrm{mmol}$ ). The mixture was stirred at room temperature for $1 \mathrm{hr}$ before a dropwise addition of a solution of 6-chloro-3-pyridylmethyl chloride $(580 \mathrm{mg}, 3.6 \mathrm{mmol})$ in DMF $(10 \mathrm{ml})$ and the stirring was continued overnight. The solvent was distilled off in vacuo, and the residual solid was extracted with hot ethanol. Precipitated crude product was recrystallized from ethanol and washed with hexane. Yield: $410 \mathrm{mg}$ (48\%), mp 129$132^{\circ} \mathrm{C}$. IR $v_{\max }(\mathrm{KBr}): 2155,1630,1275 \mathrm{~cm}^{-1}$. ${ }^{1} \mathrm{H}-\mathrm{NMR} \delta$ (acetone- $\left.d_{6}\right): 3.72(2 \mathrm{H}, \mathrm{m}), 4.53(2 \mathrm{H}, \mathrm{s}), 4.62(2 \mathrm{H}, \mathrm{m}), 7.56$ $(1 \mathrm{H}, \mathrm{d}, J=7.7 \mathrm{~Hz}), 7.86(1 \mathrm{H}, \mathrm{dd}, J=7.7,2.6 \mathrm{~Hz}), 8.41(1 \mathrm{H}, \mathrm{d}$, $J=2.6 \mathrm{~Hz}$ ). ${ }^{13} \mathrm{C}-\mathrm{NMR} \delta$ (acetone- $\left.d_{6}\right): 45.0,46.6,67.6,115.4$, 124.6, 130.7, 139.8, 149.7, 150.0, 163.5. MS m/z (\%): 236 $\left(\mathrm{M}^{+}, 18\right), 167$ (47), 126 (100). Anal. Found: C, 50.72; H, 3.80; N, 23.41\%. Calcd. for $\mathrm{C}_{10} \mathrm{H}_{9} \mathrm{ClN}_{4} \mathrm{O}: \mathrm{C}, 50.75 ; \mathrm{H}, 3.83$; $\mathrm{N}, 23.68 \%$.

3-(2-Chloro-5-thiazolylmethyl)-2-(cyanoimino)-oxazolidine (21).

Using 2-chloro-5-thiazolylmethyl chloride in place of 6chloro-3-pyridylmethyl chloride for the above reaction, the crude product was obtained. Column chromatography (silica gel, ethyl acetate) gave the product as colorless crystals in $28 \%$ yield; $m p \quad 135-138^{\circ} \mathrm{C}$. IR $v_{\max }(\mathrm{KBr}): 2190,1620$, $1270 \mathrm{~cm}^{-1} .{ }^{1} \mathrm{H}-\mathrm{NMR} \delta\left(\mathrm{CDCl}_{3}\right): 3.73(2 \mathrm{H}, \mathrm{m}), 4.60-4.64$ $(2 \mathrm{H}, \mathrm{m}), 4.62(2 \mathrm{H}, \mathrm{s}), 7.49(1 \mathrm{H}, \mathrm{s}) .{ }^{13} \mathrm{C}-\mathrm{NMR} \delta\left(\mathrm{CDCl}_{3}\right)$ : $40.8,45.7,66.8,114.5,132.7,141.3,153.2,162.7$. MS $m / z$ (\%): $242\left(\mathrm{M}^{+}, 22\right), 207$ (40), 173 (55), 132 (100). Anal. Found: C, 40.72; H, 2.80; N, 23.22\%. Calcd. for $\mathrm{C}_{8} \mathrm{H}_{7} \mathrm{ClN}_{4} \mathrm{OS}$ : C, 39.59; H, 2.91; N, 23.09\%.

1-(2-Chloropyridin-5-ylmethyl)-2-(cyanoimino)-pyrrolidine
(22).

A solution of 1-(2-chloropyridin-5-yl)-2-pyrrolidinethione ${ }^{13)}$ (233 mg, $1 \mathrm{mmol})$ and methyl iodide $(116 \mathrm{mg}, 0.82 \mathrm{mmol})$ in acetone $(34 \mathrm{ml})$ was allowed to stand at room temperature. After $12 \mathrm{hr}, 20 \mathrm{mg}$, and after a further $12 \mathrm{hr}, 10 \mathrm{mg}$ of methyl iodide were added and the mixture was allowed to stand for a total of $48 \mathrm{hr}$. The precipitated salt was quickly collected by vacuum filtration, washed with dried hexane and vacuum dried in a desiccator. The crude product $(265 \mathrm{mg})$ was treated with cyanamide $(139 \mathrm{mg}, 3.3 \mathrm{mmol})$ and 1,4-diazabicyclo[2.2.2] octane ( $23 \mathrm{mg}, 0.2 \mathrm{mmol})$, and the mixture was diluted in butanol $(5 \mathrm{ml})$. After refluxing for $3 \mathrm{hr}$ and evaporating the solvent, the residual liquid was diluted with ethyl acetate and water. The organic phase was separated and dried over magnesium sulfate. Column chromatography (silica gel, ethyl acetate) gave the crude product, which was thoroughly washed wit ether. Yield: $30 \mathrm{mg}(11 \%), \mathrm{mp} 76^{\circ} \mathrm{C}$. IR $v_{\max }(\mathrm{KBr}): 2178$, $1603 \mathrm{~cm}^{-1} .{ }^{1} \mathrm{H}-\mathrm{NMR} \delta\left(\mathrm{CDCl}_{3}\right): 2.14(2 \mathrm{H}, \mathrm{m}), 2.98(2 \mathrm{H}, \mathrm{m})$, $3.53(2 \mathrm{H}, \mathrm{m}), 4.55(2 \mathrm{H}, \mathrm{s}), 7.35(1 \mathrm{H}, \mathrm{d}, J=8.2 \mathrm{~Hz}), 7.65(1 \mathrm{H}$, $\mathrm{dd}, J=8.2,2.5 \mathrm{~Hz}), 8.31(1 \mathrm{H}, \mathrm{d}, J=2.5 \mathrm{~Hz}) .{ }^{13} \mathrm{C}-\mathrm{NMR} \delta$ $\left(\mathrm{CDCl}_{3}\right): 18.6,45.3,50.7,70.2,117.9,124.7,129.4,139.1$, 149.3, 151.6, 179.2. MS m/z (\%): $234\left(\mathrm{M}^{+}, 40\right), 199$ (30), 139 (36), 126 (75), 83 (100). Anal. Found: C, 56.51; H, 4.53; N, 24.01\%. Calcd. for $\mathrm{C}_{11} \mathrm{H}_{11} \mathrm{ClN}_{4}$ : C, 56.29; H, 4.73; N, $23.88 \%$.

\section{Biological tests}

\subsection{Chemicals}

Biological data for compound $\mathbf{2 3}$ was taken from our previous literature. ${ }^{8)}$ Reagent-grade piperonyl butoxide (PB), purchased from Tokyo Kasei Kogyo Co. (Tokyo, Japan), was used as an inhibitor of oxidative metabolism. NIA 16388 
(propargyl propyl benzenephosphonate; NIA) was the same sample used in our previous studies. ${ }^{8,14-17)}$ NIA was originally an inhibitor of the hydrolytic metabolism of pyrethroids, ${ }^{18}$ ) and was found to be a synergist for neonicotinoids in insecticidal tests. ${ }^{14)}$ Recently, Nishiwaki et al. evidenced the interference of the enzymatic hydroxylation at the imidazolidine ring of imidacloprid by NIA. ${ }^{19)}$

\subsection{Insecticidal test against American cockroaches}

The insecticidal assay against male adult American cockroaches, Periplaneta americana L., was conducted as described previously. ${ }^{8,14-17)}$ Various volumes (1-10 $\left.\mu \mathrm{l}\right)$ of each compound dissolved in methanol containing some amount of dimethyl sulfoxide (DMSO) were injected into the abdomen of a cockroach. Organic solvents alone in this range did not have a toxic effect. Details of the dosage were fundamentally the same as described previously. ${ }^{8,20)}$ The doses were varied by 1.25 times in moles. In some experiments, a methanol solution $(1 \mu \mathrm{l})$, containing PB $(50 \mu \mathrm{g})$ and NIA $(50 \mu \mathrm{g})$, was injected $1 \mathrm{hr}$ before injection of the test compound. The metabolic inhibitors in these amounts did not have a toxic effect. Three insects were used to test each dose of each compound and were kept at $22-25^{\circ} \mathrm{C}$ for $24 \mathrm{hr}$ after injection. The minimum dose at which two of three insects were considered killed was taken as the minimum lethal dose (MLD in mol). Paralyzed insects were also counted as dead. The $\log (1 / \mathrm{MLD})$ values for the test compounds are listed in Table 1 along with those previously reported. ${ }^{1)}$ Each value is the mean of at least two experiments with a deviation of 0.64-1.6 times.

\subsection{Neurophysiological assay}

The neurophysiological test of the compounds was conducted as described previously. ${ }^{8,17,21-25)}$ In brief, a nerve preparation containing the abdominal fifth and sixth ganglia of a male adult American cockroach was excised and placed in a saline solution. One of two bundles of the nerve cord was taken up

Table 1. Biological potencies of tested compounds ${ }^{a}$

\begin{tabular}{|c|c|c|c|c|c|c|c|}
\hline \multirow{2}{*}{ Compound $^{b)}$} & \multicolumn{4}{|c|}{ Insecticidal potency ${ }^{c)}$} & \multicolumn{3}{|c|}{ Neuroblocking potency ${ }^{d)}$} \\
\hline & Alone & Ratio $^{e)}$ & $+(\mathrm{PB}+\mathrm{NIA})^{f)}$ & Ratio $^{g)}$ & Obs. ${ }^{h)}$ & Calcd. ${ }^{i)}$ & Calcd.$^{j)}$ \\
\hline $\mathbf{1}\left(\mathrm{n}=0, \mathrm{Pyr}, \mathrm{NH}, \mathrm{NNO}_{2}\right)$ & 8.96 & 1 & $10.15(10.06)$ & 15 & $5.64(5.60-5.69)$ & 5.38 & 5.60 \\
\hline $2\left(\mathrm{n}=1, \mathrm{Pyr}, \mathrm{NH}, \mathrm{NNO}_{2}\right)$ & 8.22 & 5.5 & $10.12(9.78)$ & 80 & $5.35(5.26-5.44)$ & 5.56 & 5.69 \\
\hline $3\left(\mathrm{n}=0, \mathrm{Pyr}, \mathrm{NH}, \mathrm{CHNO}_{2}\right)$ & 9.19 & 0.59 & $10.19(9.72)$ & 10 & $5.02(4.95-5.09)$ & 5.17 & 5.35 \\
\hline $4\left(\mathrm{n}=0, \mathrm{Pyr}, \mathrm{CH}_{2}, \mathrm{CHNO}_{2}\right)$ & 9.84 & 0.13 & $10.44(10.78)$ & 3.9 & $6.43(6.32-6.59)$ & 6.13 & 6.09 \\
\hline $5\left(\mathrm{n}=0, \mathrm{Pyr}, \mathrm{S}, \mathrm{CHNO}_{2}\right)$ & 9.76 & 0.15 & $10.37(10.57)$ & 4.0 & $6.19(6.12-6.27)$ & 6.20 & 6.13 \\
\hline $6\left(\mathrm{n}=0\right.$, Thy, $\left.\mathrm{NH}, \mathrm{NNO}_{2}\right)$ & 8.42 & 3.5 & $9.62(9.59)$ & 16 & $5.97(5.89-6.02)$ & 5.54 & 5.67 \\
\hline $7\left(\mathrm{n}=0\right.$, Thy, $\left.\mathrm{NH}, \mathrm{CHNO}_{2}\right)$ & 9.34 & 0.42 & $10.24(9.65)$ & 8.1 & $5.73(5.58-5.87)$ & 5.58 & 5.72 \\
\hline $8\left(\mathrm{n}=0\right.$, Thy, $\left.\mathrm{CH}_{2}, \mathrm{CHNO}_{2}\right)$ & 8.96 & 1.0 & $10.06(9.85)$ & 13 & $6.31(6.17-6.46)$ & 6.50 & 6.26 \\
\hline $9\left(\mathrm{n}=0\right.$, Thy, $\left.\mathrm{S}, \mathrm{NNO}_{2}\right)$ & 7.42 & 35 & $8.91(9.42)$ & 32 & $6.00(5.92-6.09)$ & 5.69 & 5.65 \\
\hline $10\left(\mathrm{n}=0, \mathrm{Pyr}, \mathrm{NMe}, \mathrm{NNO}_{2}\right)$ & 8.53 & 2.7 & $8.62(8.72)$ & 1.3 & 3.81 & 4.22 & 4.82 \\
\hline $11\left(\mathrm{n}=0, \mathrm{Pyr}, \mathrm{NMe}, \mathrm{CHNO}_{2}\right)$ & 7.77 & 15 & $8.07(8.24)$ & 2.0 & $3.84(3.74-3.97)$ & 3.76 & 3.73 \\
\hline $12\left(\mathrm{C}=\mathrm{C}, \mathrm{Pyr}, \mathrm{NH}, \mathrm{NNO}_{2}\right)$ & 7.72 & 17 & $8.72(9.06)$ & 10 & $4.31(4.26-4.39)$ & 5.57 & 5.75 \\
\hline $13\left(\mathrm{C}=\mathrm{C}, \mathrm{Pyr}, \mathrm{S}, \mathrm{NNO}_{2}\right)$ & 8.85 & 1.3 & $10.25(10.09)$ & 25 & $5.68(5.54-5.89)$ & 5.54 & 5.70 \\
\hline $14\left(\mathrm{C}=\mathrm{C}\right.$, Thy, $\left.\mathrm{NH}, \mathrm{NNO}_{2}\right)$ & 8.12 & 6.9 & $8.82(8.66)$ & 5.1 & $4.61(4.56-4.66)$ & 5.45 & 5.68 \\
\hline $15\left(\mathrm{C}=\mathrm{C}\right.$, Thy, $\left.\mathrm{S}, \mathrm{NNO}_{2}\right)$ & 7.85 & 13 & $8.85(9.04)$ & 10 & $5.79(5.75-5.84)$ & 6.39 & 5.96 \\
\hline 16 (Pyridone, Pyr, $\mathrm{NNO}_{2}$ ) & 8.88 & 1.2 & $9.99(9.61)$ & 13 & $5.09(5.02-5.14)$ & 5.31 & 5.56 \\
\hline 17 (Pyridone, Thy, $\mathrm{NNO}_{2}$ ) & 8.92 & 1.1 & $9.74(9.35)$ & 6.7 & $5.75(5.61-5.88)$ & 5.63 & 5.69 \\
\hline 18 (n=0, Pyr, NH, NCN) & 8.42 & 3.5 & $9.52(9.54)$ & 13 & $5.37(5.30-5.47)$ & 9.46 & 5.96 \\
\hline 19 ( $\mathrm{n}=0$, Thy, NH, NCN) & 7.38 & 37 & $8.38(8.26)$ & 10 & $5.07(5.00-5.17)$ & 9.96 & 6.04 \\
\hline $20(\mathrm{n}=0, \mathrm{Pyr}, \mathrm{O}, \mathrm{NCN})$ & 8.21 & 5.6 & $9.31(9.88)$ & 29 & $5.29(5.19-5.41)$ & 8.00 & 5.24 \\
\hline 21 (n=0, Thy, O, NCN) & 7.72 & 17 & $8.52(9.32)$ & 6.3 & $5.57(5.53-5.59)$ & 8.33 & 5.42 \\
\hline $22\left(\mathrm{n}=0, \mathrm{Pyr}, \mathrm{CH}_{2}, \mathrm{NCN}\right)$ & 8.10 & 7.2 & $9.80(9.82)$ & 49 & $5.76(5.68-5.81)$ & 9.38 & 5.88 \\
\hline $\mathbf{2 3}^{k)}(\mathrm{n}=0, \mathrm{Pyr}, \mathrm{S}, \mathrm{NCN})$ & 7.68 & 19 & $9.68(9.37)$ & 100 & $5.59(5.57-5.60)$ & 9.40 & 5.68 \\
\hline
\end{tabular}

${ }^{a)}$ Biological data for compounds 1 to 17 were taken from Ref. $1 .{ }^{b)}$ See Fig. $\left.1 .{ }^{c}\right) \log (1 / \mathrm{MLD})(\mathrm{mol}) .{ }^{d)} \log (1 / \mathrm{BC})(\mathrm{M}) .{ }^{e}$ MLD (in mol) ratio to that of imidacloprid (1). ${ }^{f)}$ Values in parentheses are calculated from Eq. $5 .{ }^{g}{ }^{g}$ Ratio of MLD (PB+NIA) to MLD (Alone) in mol. ${ }^{h)}$ Values in parentheses indicate the range of error estimated from standard deviation. ${ }^{i)}$ Calculated from a reported equation ${ }^{l}$ derived from compounds 1-11, 13, and 15-17. ${ }^{j)}$ Calculated from Eq. $4 .{ }^{k)}$ Thiacloprid, biological data taken from Ref. 8. ${ }^{l)}$ Cited from Ref. 1. 
from the thoracic side with saline into a glass tube, in which a silver wire was set as an electrode. As the reference electrode, another wire was set outside the cut end of the tube. The silver wires were thinly coated with silver chloride. The number of spontaneous discharges larger than approximately $15 \mu \mathrm{V}$ was consecutively counted with a pulse counter (MET-1100, Nihon Kohden, Tokyo) for every $30 \mathrm{sec}$ period. The frequency was usually quite high for a few minutes after setting, and then normally subsided. When the frequency decreased at around a range of $30-400$ counts per $30 \mathrm{sec}$ for about $2 \mathrm{~min}$, the saline solution was exchanged for a fresh saline containing a test compound dissolved in methanol containing some amount of DMSO. The final concentration of the organic solvents was lower than $1 \%(\mathrm{v} / \mathrm{v})$, which did not affect the nerve activity. Measurements were conducted at $22-25^{\circ} \mathrm{C}$. The neuroblocking concentrations of compounds ( $\mathrm{BC}$ in $\mathrm{M}$ ) to suppress the frequency below 10 counts $/ 30 \mathrm{sec}$ as defined previously. ${ }^{1,8)}$ Their $\log$ values are listed in Table 1 along with those previously reported. ${ }^{1)}$

\section{Hydrophobicity parameter}

$\log P$, where $P$ is the partition coefficient of compounds in the 1-octanol/water partitioning system, was determined by the shaking-flask method. ${ }^{22)}$ The concentration of compounds in the water phase was measured by HPLC using an ODS column (LiChrosorb RP-18, Merck, Darmstadt, Germany) with a mixture of acetonitrile and water ( $3: 7$ to $1: 1$ by volume) as the mobile phase.

\section{Quantum chemistry calculations}

The geometry optimization was carried out at the B3LYP/6$31 \mathrm{G}(\mathrm{d})$ level using the Gaussian 98 program. ${ }^{26)}$ The optimized geometries were confirmed with no imaginary frequencies by the vibrational analyses. We used the Mulliken charges to evaluate the charges at $\mathrm{C} 2, \mathrm{C} 4, \mathrm{C} 5, \mathrm{C} 6, \mathrm{X}$, and $\mathrm{N}$ in compounds 18-23. The calculated charges are summarized together with those for compounds $\mathbf{1 - 1 7}$ in Table 2 (also see Fig. 2). The detailed calculation procedures for all the compounds listed are available from Y. N. (naruse@apchem.gifuu.ac.jp).

\section{Correlation analysis}

Variations in the neuroblocking activity were analyzed by using free energy related physicochemical parameters of compounds according to Eq. 1,27,28)

$$
\log (1 / \mathrm{BC})=a Q+b(\log P)-c(\log P)^{2}+d S-e S^{2}+\text { constant }
$$

where $Q$ represents the Mulliken charges of compounds represented in Fig. 2, and $\log P$ is the hydrophobicity parameter listed in Table 2. $S$ is the steric parameter of the compounds. To determine the existence of an optimum in the hydrophobicity and steric dimensions, the squared parameter terms were added so that $c$ and $e \geq 0$.
We examined the relationship between the insecticidal activity against American cockroaches, which was measured with the synergists, and the neuroblocking activity with the American cockroach nerve cord using Eq. 2. ${ }^{29)}$

$$
\log (1 / \mathrm{MLD})=a(\log 1 / \mathrm{BC})+b(\log P)-c(\log P)^{2}+\text { constant }
$$

The squared $\log P$ term was added to identify the optimum hydrophobic effect, so that $c \geq 0$. Coefficients $a, b$ and $c$ and the constant in the equations were determined by the leastsquares method. Unless otherwise noted, statistical significance levels of the correlation equations and the independent terms in each equation were above $95 \%$ as examined by the $t$ test.

\section{Results and Discussion}

\section{Insecticidal potency and the synergistic effect}

The cyanoimine derivatives showed strong insecticidal activity without the metabolic inhibitors (alone) with the minimum lethal dose (MLD) of about $10 \mathrm{nmol}, 7.5-8.5$ in $\log (1 / \mathrm{MLD})$ units, although they were generally lower than the corresponding nitromethylene or nitroimine compounds. Interestingly, the derivatives of imidazolidine, oxazolidine and pyrrolidine $(\mathbf{1 8}, \mathbf{2 0}, \mathbf{2 2})$ were apparently higher than the commercialized thiazolidine derivative (23) in activity. As for the appending heteroaromatic nucleus, the activity of the chloropyridyl residue was greater than the chlorothiazolyl, as in the nitro compounds. ${ }^{1)}$

In principle, the insecticidal potency improves when synergists eliminate or minimize the enzymatic metabolism. We have thus far observed the activity enhancement of neonicotinoid compounds by the presence of $\mathrm{PB}$ and NIA. ${ }^{1,8,14,16,17,21-23,30,31)}$ Also, in the present case, the potency improvement was observed in all compounds. The high synergistic effect for compound $\mathbf{2 3}$ was noticeable; the potency was enhanced by factor 2. The oxidation is a major metabolic pathway for neonicotinoids, and the synergists, PB and NIA, were proved to interfere with this enzymatic action. ${ }^{19)}$ The high synergistic effect of compound $\mathbf{2 3}$ is crucially due to the sulfide moiety sensitive to the enzymatic oxidation in the absence of synergists, as observed in other neonicotinoid sulfide derivatives, ${ }^{1,8)}$ and Ford and Casida actually observed the facile oxidation of thiacloprid to the SO-derivative in the brain, liver and plasma in intraperitoneally administrated mice. $^{32)}$

One of the major oxidation metabolic pathways for imidacloprid assures the hydroxylation at the $\mathrm{C} 4 / \mathrm{C} 5$ position and the subsequent dehydration in plants, ${ }^{33,34)}$ mice, ${ }^{32)}$ houseflies $^{19)}$ and human cytochrome. ${ }^{35)}$ In our earlier experiment, these metabolites showed lower insecticidal activity against American cockroaches. ${ }^{25}$ Nishiwaki et al. showed that this metabolic path is disrupted by adding PB and NIA. ${ }^{19)}$ In this respect, we can predict that the synergistic ratio will be larger for a compound with a larger electron density at the target 
Table 2. Calculated Mulliken charges and partition coefficients of selected compounds

\begin{tabular}{|c|c|c|c|c|c|c|c|c|}
\hline \multirow{2}{*}{ Type } & \multicolumn{2}{|c|}{ Structure } & \multicolumn{4}{|c|}{ Mulliken charges $^{a)}$} & \multicolumn{2}{|c|}{$\log P^{b)}$} \\
\hline & $\mathrm{X}$ & $\mathrm{Y}$ & $\mathrm{N}-\mathrm{Me}$ & $\mathrm{C} 2 / \mathrm{C} 4 / \mathrm{C} 5 / \mathrm{C} 6$ & $\mathrm{X}$ & $\mathrm{O} 1 / \mathrm{O} 2(\mathrm{~N})$ & Pyr & Thy \\
\hline I & $\mathrm{NH}$ & $\mathrm{N}$ & -0.468 & $0.834 / 0.208 / 0.194 /-$ & -0.253 & $-0.470 /-0.398$ & $\begin{array}{c}1 \\
(0.53)\end{array}$ & $\begin{array}{c}6 \\
(0.61)\end{array}$ \\
\hline II & $\mathrm{NMe}$ & $\mathrm{N}$ & -0.461 & $0.810 / 0.195 / 0.188 /-$ & -0.449 & $-0.429 /-0.399$ & $\begin{array}{c}10 \\
(-0.07)\end{array}$ & \\
\hline III & $\mathrm{NH}$ & $\mathrm{CH}$ & -0.486 & $0.630 / 0.205 / 0.184 /-$ & -0.268 & $-0.490 /-0.435$ & $\begin{array}{c}\mathbf{3} \\
(-0.18)\end{array}$ & $\begin{array}{l}7 \\
(0.03)\end{array}$ \\
\hline IV & $\mathrm{NMe}$ & $\mathrm{CH}$ & -0.472 & $0.638 / 0.193 / 0.178 /-$ & -0.471 & $-0.463 /-0.432$ & $\begin{array}{c}11 \\
(-0.84)\end{array}$ & \\
\hline V & $\mathrm{NH}$ & $\mathrm{N}$ & -0.471 & $0.832 / 0.216 / 0.026 / 0.189$ & -0.258 & $-0.484 /-0.401$ & $\begin{array}{l}\mathbf{2} \\
(0.57)\end{array}$ & \\
\hline VI & $\mathrm{CH}_{2}$ & $\mathrm{CH}$ & -0.441 & $0.416 / 0.019 / 0.185 /-$ & 0.043 & $-0.453 /-0.426$ & $\begin{array}{l}4 \\
(0.45)\end{array}$ & $\begin{array}{c}8 \\
(0.64)\end{array}$ \\
\hline VII & $\mathrm{S}$ & $\mathrm{N}$ & -0.401 & $0.385 /-0.082 / 0.217 /-$ & 0.263 & $-0.416 /-0.391$ & & $\begin{array}{l}9 \\
(0.80)\end{array}$ \\
\hline VIII & $\mathrm{S}$ & $\mathrm{CH}$ & -0.402 & $0.143 /-0.081 / 0.203 /-$ & 0.264 & $-0.434 /-0.427$ & $\begin{array}{l}\mathbf{5} \\
(0.47)\end{array}$ & \\
\hline IX & $\mathrm{NH}$ & $\mathrm{N}$ & -0.472 & $0.823 / 0.216 / 0.195 /-$ & -0.243 & $-0.493 /-0.416$ & $\begin{array}{l}12 \\
(0.33)\end{array}$ & $\begin{array}{l}14 \\
(0.27)\end{array}$ \\
\hline $\mathrm{X}$ & $\mathrm{S}$ & $\mathrm{N}$ & -0.414 & $0.365 /-0.215 / 0.292 /-$ & 0.360 & $-0.432 /-0.403$ & $\begin{array}{l}13 \\
(0.53)\end{array}$ & $\begin{array}{l}15 \\
(0.96)\end{array}$ \\
\hline XI & $\mathrm{CH}$ & $\mathrm{N}$ & -0.467 & $0.581 / 0.064 / 0.265 /-0.022$ & 0.035 & $-0.441 /-0.397$ & $\begin{array}{l}16 \\
(0.51)\end{array}$ & $\begin{array}{l}17 \\
(0.67)\end{array}$ \\
\hline XII & $\mathrm{NH}$ & & -0.464 & $0.769 / 0.200 / 0.196 /-$ & -0.278 & $(-0.506)$ & $\begin{array}{l}\mathbf{1 8} \\
(0.83)\end{array}$ & $\begin{array}{l}19 \\
(1.08)\end{array}$ \\
\hline XIII & $\mathrm{O}$ & & -0.461 & $0.801 / 0.303 / 0.187 /-$ & -0.469 & $(-0.490)$ & $\begin{array}{l}20 \\
(0.35)\end{array}$ & $\begin{array}{l}21 \\
(0.52)\end{array}$ \\
\hline XIV & $\mathrm{CH}_{2}$ & & -0.420 & $0.555 / 0.026 / 0.195 /-$ & 0.025 & $(-0.501)$ & $\begin{array}{l}22 \\
(0.87)\end{array}$ & \\
\hline $\mathrm{XV}$ & $\mathrm{S}$ & & -0.391 & $0.337 /-0.052 / 0.217 /-$ & 0.206 & $(-0.488)$ & $\begin{array}{l}\mathbf{2 3} \\
(1.09)\end{array}$ & \\
\hline
\end{tabular}

a) Hydrogens are summed into the heavy atoms. ${ }^{b)} \log P$ in parentheses notes the log of the partition between octanol and water; the bold figure stands for the number of the corresponding compound.

site(s). The synergistic ratio order of 4, 1.7 and 1.1 among the derivatives of pyrrolidine (22), imidazolidine (18), oxazolidine (20), respectively, can be explained by the order of their Mulliken charge magnitudes on their C4s (Table 2) under the assumption that the metabolites of the pyrrolidine and the oxazolidine derivatives have similar activity tendency to the imidazolidine one. The obviously low synergistic ratio of 0.4 for nitromethylene-pyrrolidine (4) compared with 1.7 for cyanoimine derivative (22) despite having the almost same charge values was noted. We cannot see any notable difference between them in the metabolic sensitivity. In general, an inherently highly active compound does not show a drastic activity drop until a substantial amount of the active structure is decomposed. This is the case of compound $\mathbf{4}$ displaying the modest synergistic effects compared with compound $\mathbf{2 2}$.

Although we could account for some qualitatively relations of the insecticidal potencies to the physicochemical factors for individual pairs, no clear quantitative relationship was found between the Mulliken charges and the $\log (1 / \mathrm{MLD})$ measured with the synergists for the listed whole compounds. 


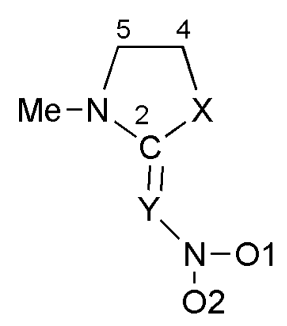

I-IV, VI-VIII

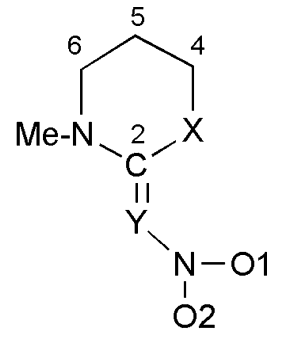

V

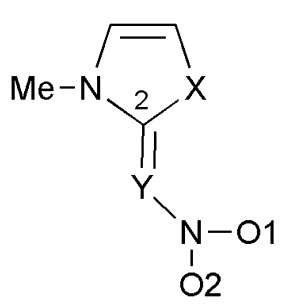

$\mathbf{I X}, \mathbf{X}$<smiles></smiles>

$\mathbf{X I}$

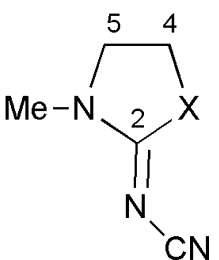

XII-XV

Fig. 2. Structure types for the atomic charge in Table 2.

\section{Neuroblocking potency}

The primary target of neonicotinoid insecticides is the $\mathrm{nAChR}$. Cation-permeable ion channels of the nAChR desensitize in response to full occupation of the ligand binding sites with acetylcholine. Thus, prolonged exposure of the nAChR to nonhydrolyzable agonists such as thiacloprid results in blocking cholinergic neurotransmission. The excitation duration time (the time until the blocking begins) and the frequency of nerve impulses are in principle proportional to the binding capacity to the receptor and the quantity of the ligand on it. The neuroexcitation or neuroblocking capacity of a ligand can be estimated by comparing the minimum concentration to induce the two-phase electric episode. ${ }^{17,21,37)}$ Generally, the dose for excitation of the nerve is smaller than that for the following blockade. Between these two effects, the neuroblocking measurements seems to be related more significantly to the insecticidal tendency than the neuroexcitation, so we evaluated only the $\mathrm{BC}$ in the present study. ${ }^{17,21)}$

\section{Quantitative analysis of the neuroblocking potencies}

The present cyanoimine compounds elicited a neuroblocking effect at the micromolar level, and the pyrrolidine compound (22) surpassed imidacloprid (1). Such high activity is understandable from the conjugation system composed of an electron-donating guanidine part and the powerful electron-withdrawing group NCN, a framework similar to the nitroimino and nitromethylene analogs (Fig. 3). The Mulliken charge map delineates the pharmacophoric figure of the positively charged pivotal carbons $(\mathrm{C} 2)$ at the guanidine part and the tip cyano $\mathrm{N}$ atom with large negative charge (Table 2). Together with the pharmacophoric requirements, the lipophilicity/ hydrophilicity factor such as octanol-water partition $\left(P_{\mathrm{OW}}\right)$ plays an important role in the activity exhibition. ${ }^{1,14,16,38,39)}$ We measured the $\log P$ values of the present cyanoimine compounds and noticed that they were more lipophilic than the corresponding nitro compounds (Table 2).

In the foregoing paper dealing with nitroimino and nitromethylene compounds $\mathbf{1 - 1 7}$, we found a significant correlation between the neuroblocking potency and the physicochemical parameters using the Mulliken charge $\left(Q_{\mathrm{O} 2}\right)$ on the nitro oxygen atom $\mathrm{O} 2$ and the $\log P .{ }^{1)}$ Since the number of the present cyanoimino compounds $\mathbf{1 8} \mathbf{- 2 3}$ is too small to independently analyze quantitatively their physicochemical parameters, we examined if the foregoing results can integrate the present cyanoimino compounds by using Mulliken charge $\left(Q_{\mathrm{O} 2, \mathrm{~N}}\right)$ in this class on the tip $\mathrm{N}$ atom of the $\mathrm{NCN}$ group. As listed in Table 1, the values calculated for compounds 18-23 by the previously derived equation ${ }^{1)}$ seemed to be divided into two groups. The values for compounds 20-23 are greater by 2.7-3.8 than the observed values, while those of $\mathbf{1 8}$ and $\mathbf{1 9}$ are still more deviated. After trials with additional parameters, we derived the following equation as the best one by excluding compounds $\mathbf{1 2}$ and $\mathbf{1 4}$, as done previously, ${ }^{1)}$ and $\mathbf{1 8}$ and $\mathbf{1 9 .}$

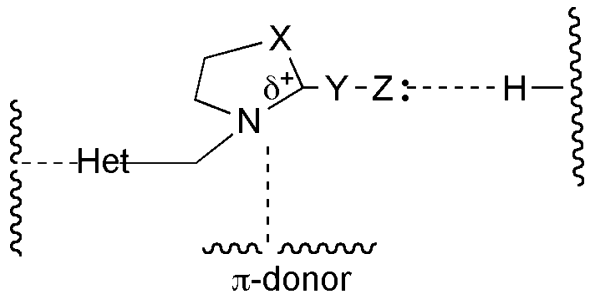<smiles>C=[V]N1NC(NC)NC[C]O1</smiles>

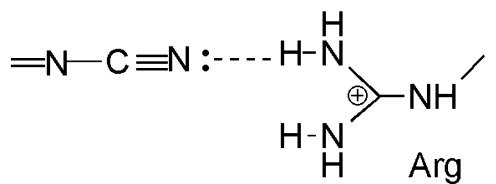

(ii)

Fig. 3. Schematic mode for binding of neonicotinoid to $n A C h R$ $\left(\mathrm{X}=\mathrm{N}, \mathrm{CH}_{2}, \mathrm{~S} ; \mathrm{Y}=\mathrm{N}, \mathrm{CH} ; \mathrm{Z}=\mathrm{NO}_{2}, \mathrm{CN}\right.$ ). The $\mathrm{Z}$ group, the electrondeficient moiety $(\delta+)$ of the central ring, and the heteroaromatic nucleus (depicted as Het) approach the recognition site on the nAChR through $\mathrm{H}$-bond (below i and/or ii), via the $\pi$-donor-acceptor interaction, and in an auxiliary way, respectively. 


$$
\begin{aligned}
\log (1 / \mathrm{MBC})= & -6.389( \pm 5.762)-27.651( \pm 13.767)\left(Q_{\mathrm{O} 2, \mathrm{~N}}\right) \\
& +1.885( \pm 0.508)(\log P) \\
& -0.552( \pm 0.614)(\log P)^{2} \\
& -2.680( \pm 1.275) I_{\mathrm{NCN}} \\
n= & 19, s=0.337, r=0.906, F_{4,14}=16.08
\end{aligned}
$$

In Eq. 3, $I_{\mathrm{NCN}}$ was set at unity for compound $\mathbf{2 3}$ with $\mathrm{NCN}$ groups, but was set at zero for other compounds. In this and the following equations, $n$ is the number of compounds, $s$ is the standard deviation, $r$ is the correlation coefficient, and $F$ is the value of the ratio between regression and residual variances. The figures in parentheses following the intercept and the regression coefficients are their $95 \%$ confidence intervals.

From careful examination of the results, the $\log (1 / \mathrm{BC})$ value calculated by Eq. 3 for compound $\mathbf{1 0}$ seemed to be much higher than the experimentally measured value (data not shown). By also excluding this compound, Eq. 3 was much improved to give Eq. 4.

$$
\begin{aligned}
\log (1 / \mathrm{MBC})= & -3.103( \pm 4.992)-20.160( \pm 11.824)\left(Q_{\mathrm{O} 2, \mathrm{~N}}\right) \\
& +1.647( \pm 0.426)(\log P) \\
& -0.694( \pm 0.487)(\log P)^{2} \\
& -2.028( \pm 1.084) I_{\mathrm{NCN}} \\
n= & 18, s=0.260, r=0.921, F_{4,13}=18.19 .
\end{aligned}
$$

Addition of the steric terms for compounds such as Vw and/or $(\mathrm{Vw})^{2}$, where $\mathrm{Vw}$ is a van der Waals volume, ${ }^{40)}$ did not improve the equation. This equation indicates that the neuroblocking potency is primarily proportional to the Mulliken charge magnitude on the tip atom on the pharmacophore, and is also related to the $\log P$ term with the optimal value of 1.19. The activities calculated by Eq. 4 are listed in Table 1 .

The electronegative tip(s) of neonicotinoids has been assumed to electrostatically interact with the positively charged residue (Arg/Lys) of insect nAChR, ${ }^{9,10)}$ or through an $\mathrm{H}$-bond with (Cys/Tyr) of a mollusk ACh binding protein. ${ }^{41)}$ The pharmacophore bearing a more electronegative tip is predicted to induce stronger nerve impulses. The negative charge magnitudes on the blocking activity of the cyanoimine compounds are adjusted lower than the corresponding nitroimino compounds with a similar Mulliken charge as indicated in the equation appending the $I_{\mathrm{NCN}}$ term of the coefficient -2.03 .

According to the preliminary calculations performed only with PM3 Hamiltonian using MNDO optimized structures, the Mulliken charge magnitudes on the nitro oxygen atoms of imidacloprid (1) are (negatively) larger than on the cyano nitrogen atom of thiacloprid (23). ${ }^{42)}$ In the present paper, calculations were performed at the B3LYP/6-31G(d) level, which includes the electronic factors, to evaluate the charges of a series of the analogue compounds (i.e. the effect of the hetero atom of the center ring) more precisely. As a result, the negative charge magnitude on the cyano $\mathrm{N}$ atom of thiacloprid was obviously larger than that on the corresponding nitro oxygen atoms of imidacloprid. We presume this is because the single nitrogen atom offsets the positive net charge in cyanoimine, while two oxygen atoms have this role in nitro groups. This quantum chemical result of the negative charge magnitude may lead to the prediction that cyano compounds are more active than nitro compounds, opposite to the actual tendency.

According to the binding figure, the distance of $2.7 \AA$ from the cyano $\mathrm{N}$ atom to the $\mathrm{NH}$ of loop $\mathrm{C}-190$ on the receptor is apparently longer than the distance $2.2 \AA$ from the nitro $\mathrm{O} 2$ atom. ${ }^{41)}$ Additionally, the following argument disadvantages the NCN group; thus, the nitro group can make an H-bond with two hydrogen atoms of the arginine residue, ${ }^{10,43)}$ an important recognizing residue, in a bidentate form (i) and such cooperative bonding will be thermodynamically more favorable than the monodentate H-bond (ii) (Fig. 3). We attribute the inferior effect of the cyanoimines to the nitro compounds to these combined stereoelectronic factors. This argument also explains the reported weaker binding of the $N$-nitroso $(-\mathrm{NN}=\mathrm{O})$ compound than the nitroimino compound (imidacloprid) for Drosophila nAChR. ${ }^{44)}$

Biological activity is determined not only by the pharmacodynamics involved in the pharmacophore, but also by pharmacokinetic factors such as lipophilicity/hydrophilicity related to the properties of the whole molecule. Equation 4 indicates the optimal value 1.19 for $\log P$; consequently, markedly hydrophilic compounds such as 3, 10 and 11, and, as opposed, fairly lipophilic compounds such as compounds 19 and 23 tend to lower neuroblocking potency, even if they fulfill the pharmacophoric requirements.

For the deviation of compounds $\mathbf{1 2}$ and $\mathbf{1 4}$ from Eq. 4, we consider that a different factor is needed for compounds bearing the strongly acidic $\mathrm{NH}$ proton ${ }^{25,33)}$ to determine ligandreceptor interaction. Another outlier was compound 10. Although there would be an argument that such compounds lacking the intramolecular H-bonding capacity should be separately treated from those with this capacity, we are doubtful that intramolecular H-bonds can occur in an aquatic biophase. ${ }^{45)}$ In fact, we could not observe any improvement in the calculation by separating two types of compounds, the intramolecular H-bonding-capable compounds 1-3, 6, 7, 12 and 14, and the incapable compounds. Instead, we propose the following explanation. In the crystal structure of 10, the nitro group is rotated almost perpendicularly out of the guanidine plane owing to the large steric constraint. ${ }^{46)}$ Overall, this skeleton is also possibly retained in the tested milieu; therefore, such a molecule where the $\pi$-conjugation on the key pharmacophore is heavily distorted may not be treated in the same category. Compound $\mathbf{1 1}$ bearing a similar structural framework was indicated in Eq. 4. The longer bond distance of $\mathrm{C}=\mathrm{C}(1.383 \AA)$ than $\mathrm{C}=\mathrm{N}(1.317 \AA)$ would lessen the repulsion between the residues of $\mathrm{NO}_{2}$ and $\mathrm{Me}$; dihedral angles of compounds $\mathbf{1 0}$ and $\mathbf{1 1}$ lie $24.1^{\circ}$ and $14.0^{\circ}$ respectively (unpublished calculation). The reason why compounds $\mathbf{1 8}$ and 19 had larger values in each equation than their actual potencies is currently unclear. 


\section{Relation between Neuroblocking and insecticidal Potencies}

Although the $\log (1 / \mathrm{MLD})$ values measured with the synergists did not show any clear quantitative relationship with the Mulliken charges, we could derive the following equation between the insecticidal and the neuroblocking potencies by referring to Eq. 2.

$$
\begin{aligned}
\log (1 / \mathrm{MLD})= & 5.507( \pm 1.334)+0.843( \pm 0.252)(\log 1 / \mathrm{BC}) \\
& -0.716( \pm 0.495)(\log P)^{2} \\
& -0.684( \pm 0.359) I_{\text {Thy }} \\
n= & 23, s=0.382, r=0.873, F_{3,19}=20.32 .
\end{aligned}
$$

In Eq. $5, I_{\text {Thy }}$ was set at unity for compounds $6-9, \mathbf{1 4}, \mathbf{1 5}, \mathbf{1 7}$, 19 and 21 with a thiazolyl ring as the aromatic ring, but was set at zero for other compounds. Insecticidal activities calculated by Eq. 5 are listed in Table 1. The coefficient of the $I_{\text {Thy }}$ term means that the insecticidal activity of the chloropyridyl compounds was about 4.8 times higher than the chlorothiazolyl compounds when other factors were the same. Furthermore, Eq. 5 indicates that the high neuroblocking activity gives the potent insecticidal activity in a proportional manner with a slope of unity if one considers the range of error. Addition of the $\log P$ term to Eq. 5 or replacement of the $(\log P)^{2}$ term by the $\log P$ term did not improve the quality of the equation. The equation shows that the insecticidal activity was parabolically related to the $\log P$ value with an optimum of around zero. Similar parabolic relations were observed in such cases as the insecticidal activity against American cockroaches for other series of neonicotinoids with the neuroblocking ${ }^{17,21)}$ and with the neuroexcitatory ${ }^{14,16)}$ activities.

In conclusion, most of the variations of the pharmacophore structure bearing $\mathrm{NNO}_{2}, \mathrm{CHNO}_{2}$, or $\mathrm{NCN}$ in neonicotinoids afforded insecticidal activity against American cockroaches at nanomolar concentrations under synergistic conditions. The neuroblocking potency was proportional to the Mulliken charge on the nitro oxygen atom or the cyano nitrogen atom, and was related to the $\log P$ value with the optimal value of 1.19. The potency of NCN compounds was lower by a factor of 2.03 in log units than the corresponding nitro compounds in the neuroblocking activity. A quantitative relation between the neuroblocking activity and the insecticidal activity was observed, which suggests that the common nervous system of $\mathrm{nAChR}$ is the primary and fatal target for neonicotinoid insecticides. Theories at various levels and experiments using several known molecules have predicted or speculated the crucial involvement of the presented structural part in the activity of neonicotinoids thus far. Our present and previous QSAR studies using a set of structural variations have evidently proved the function as the key pharmacophore.

\section{Acknowledgement}

We are grateful to Prof. Satoshi Inagaki for valuable suggestions.

\section{References}

1) S. Kagabu, R. Ishihara, Y. Hieda, K. Nishimura and Y. Naruse: J. Agric. Food Chem. 55, 812-818 (2007).

2) K. Shiokawa, S. Tsuboi, S. Kagabu, S. Sasaki, K. Moriya and Y. Hattori (Nihon Tokushu Noyaku Seizo Co. Ltd.): Jpn. Tokkyo Koho JP 62-207266 (1987).

3) M. Esters (ed): Pflanzenschutz-Nachr. Bayer 54, 145-306 (2001).

4) T. Yamada, H. Takahashi and R. Hatano: "Nicotinoid Insecticides and the Nicotinic Acetylcholine Receptor," ed. by I. Yamamoto and J. E. Casida, Springer, Tokyo, Chapter 7, 1999.

5) S. Kagabu: Rev. Toxicol. 1, 75-129 (1997).

6) A. Nakayama and M. Sukekawa: Pestic. Sci. 52, 104-110 (1998).

7) A. Okazawa, M. Akamatsu, A. Ohoka, H. Nishiwaki, W.-J. Cho, Y. Nakagawa, K. Nishimura and T. Ueno: Pestic. Sci. 54, 134144 (1998).

8) S. Kagabu, A. Azuma and K. Nishimura: J. Pestic. Sci. 27, 267-271 (2002).

9) M. Tomizawa and J. E. Casida: Annu. Rev. Entomol. 48, 339364 (2003).

10) K. Matsuda, M. Shimomura, M. Ihara, M. Akamatsu and D. B. Sattelle: Biosci. Biotechnol. Biochem. 69, 1442-1452 (2005).

11) S. Kagabu, K. Yokoyama, K. Iwaya and M. Tanaka: Biosci. Biotechnol. Biochem. 62, 1216-1224 (1998).

12) M.-Y. Liu, B. Latli and J. E. Casida: Pestic. Biochem. Physiol. 52, 170-181 (1995).

13) B. Latli, K. D'Amour and J. E. Casida: J. Med. Chem. 42 , 2227-2234 (1999).

14) K. Nishimura, Y. Kanda, A. Okazawa and T. Ueno: Pestic. Biochem. Physiol. 50, 51-59 (1994).

15) S. Kagabu, N. Ito, R. Imai, Y. Hieda and K. Nishimura: J. Pestic. Sci. 30, 409-413 (2005).

16) K. Nishimura, M. Tanaka, K. Iwaya and S. Kagabu: Pestic. Biochem. Physiol. 62, 172-178 (1998).

17) K. Kiriyama, K. Iwaya, S. Kagabu and K. Nishimura: J. Pestic. Sci. 26, 55-59 (2001).

18) T. Suzuki and J. Miyamoto: Pestic. Biochem. Physiol. 4, 86-97 (1974).

19) H. Nishiwaki, K. Sato, Y. Nakagawa, M. Miyashita and H. Miyagawa: J. Pestic. Sci. 29, 110-116 (2004).

20) S. Kagabu, Y. Itazu and K. Nishimura: J. Pestic. Sci. 29, 40-42 (2004).

21) K. Kiriyama and K. Nishimura: Pest Manag. Sci. 58, 669-676 (2002).

22) K. Kiriyama, Y. Itazu, S. Kagabu and K. Nishimura: J. Pestic. Sci. 28, 8-17 (2003).

23) S. Kagabu, K. Kiriyama, H. Nishiwaki, Y. Kumamoto, T. Tada and K. Nishimura: Biosci. Biotechnol. Biochem. 67, 980-988 (2003).

24) K. Kiriyama, S. Kagabu and K. Nishimura: J. Pestic. Sci. 29, 43-45 (2004).

25) S. Kagabu, C. Kato and K. Nishimura: J. Pestic. Sci. 29, 376379 (2004).

26) J. R. Frisch, G. W. Trucks, H. B. Schlegel, G. E. Scuseria, M. A. Robb, M. J. Cheeseman, V. G. Zakrzewski, J. A. Montgomery, 
R. E. Stratmann, J. C. Burant, S. Dapprich, J. M. Millam, A. D. Daniels, K. N. Kudin, M. C. Strain, O. Farkas, J. Tomasi, V. Barone, M. Cossi, R. Cammi, B. Mennucci, C. Pomelli, C. Adamo, S. Clifford, J. Ochterski, G. A. Petersson, P. Y. Ayala, Q. Cui, K. Morokuma, D. K. Malick, A. D. Rabuck, K. Raghavachari, J. B. Foresman, J. Cioslowski, J. V. Ortiz, A. G. Baboul, B. B. Stefanov, G. Liu, A. Liashenko, P. Piskorz, I. Komaromi, R. Gomperts, R. L. Martin, D. J. Fox, T. Keith, M. A. Al-Laham, C. Y. Peng, A. Nanayakkara, C. Gonzalez, M. Challacombe, P. M. W. Gill, B. Johnson, W. Chen, M. W. Wong, J. L. Andres, C. Gonzalez, M. Head-Gordon, E. S. Replogle and J. A. Pople: GAUSSIAN98 Revision A.7. Gaussian, Inc., Pittsburgh PA, 1998.

27) C. Hansch and T. Fujita: J. Am. Chem. Soc. 86, 1616-1626 (1964).

28) S. Nakagawa, N. Okajima, K. Nishimura, T. Fujita and M. Nakajima: Pestic. Biochem. Physiol. 17, 259-270 (1982).

29) S. Nakagawa, K. Okajima, T. Kitahaba, K. Nishimura, T. Fujita and M. Nakajima: Pestic. Biochem. Physiol. 17, 243-258 (1982).

30) S. Kagabu, N. Murata, R. Hibino, M. Hanzawa and K. Nishimura: J. Pestic. Sci. 30, 111-115 (2005).

31) S. Kagabu, N. Ito, R. Imai, Y. Hieda and K. Nishimura: J. Pestic. Sci. 30, 409-413 (2005).

32) K. A. Ford and J. E. Casida: Chem. Res. Toxicol. 19, 944-951 (2006).

33) R. Nauen, U. Reckmann, S. Armborst, H.-P. Stupp and A. Elbert: Pestic. Sci. 55, 265-271 (1999).
34) J. Thyssen and L. Machemer: "Nicotinoid Insecticides and the Nicotinic Acetylcholine Receptor," ed. by I. Yamamoto and J. E. Casida, Springer, Tokyo, Chapter 9, 1999.

35) D. A. Schulz-Jander and J. E. Casida: Toxicol. Lett. 132, 65-70 (2002).

36) M. Tokieda, M. Ozawa, S. Kobayashi, T. Gomyo and M. Takeda: J. Pestic. Sci. 24, 115-122 (1999).

37) K. Nishimura, K. Kiriyama and S. Kagabu: J. Pestic. Sci. 31, 110-115 (2006).

38) S. Kagabu and S. Medej: Biosci. Biotechnol. Biochem. 59, 980-985 (1995).

39) S. Kagabu: "Chemistry of Crop Protection, Progress and Prospects in Science and Regulation," ed by G. Voss and G. Ramos, Wiley-VCH, Weinheim, pp. 193-212 (2003).

40) A. Bondi: J. Phys. Chem. 80, 1799-1806 (1976).

41) M. Tomizawa, T. T. Talley, D. Maltby, K. A. Durkin, K. F. Medzihradszky, A. L. Burligame, P. Taylor and J. E. Casida: Proc. Natl. Acad. Sci. U.S.A. 104, 9075-9080 (2007).

42) M. Tomizawa, D. L. Lee and J. E. Casida: J. Agric. Food Chem, 48, 6016-6024 (2000).

43) Y. Wang, J. Cheng, X. Qian and Z. Li: Bioorg. Med. Chem. 15, 2624-2630 (2007).

44) M. Tomizawa, N. Zhang, K. A. Durkin, M. M. Olmstead and J. E. Casida: Biochemistry 42, 7819-7827 (2003).

45) G. A. Jeffrey: "An Introduction to Hydrogen Bonding”, Oxford Univ. Press, Oxford, 1997, Chapter 4.

46) S. Kagabu and H. Matsuno: J. Agric. Food Chem. 45, 276-281 (1997). 